\title{
Leiomyosarcoma and Endometrial Stromal Sarcoma cM0 TNM Finding v7
}

National Cancer Institute

\section{Source}

National Cancer Institute. Leiomyosarcoma and Endometrial Stromal Sarcoma cMo

TNM Finding v7. NCI Thesaurus. Code C89604.

No distant metastasis. (from AJCC 7th Ed.) 